\title{
Singularities and Discontinuites of the Triangle Graph, as a Functions of an Internal Mass.
}

\author{
I. J. R. AItchison \\ High-Energy Physics Group, Cavendish Laboratory - Cambridye \\ C. KACSER \\ Physics Department, The Universfty of Maryland - Oollege Park, Md. \\ (Nuovo Cimento, $40 \mathrm{~A}, 576(1965))$ \\ The right-hand sides of each of the following equations should be multiplied by \\ a single extra factor of $\pi$ : eqs. $(6 a),(6 b),(7),(9),(10)$ and the final equation. \\ (Cf.: The discontinuities of the triangle graph, C. KACSER: Journ. Math. Phys., 7,
} to appear (1966)).

\section{Comparison of $\mathrm{K}^{ \pm} \mathrm{p}$ Dispersion Relations with Experiment.}

M. Lustgnoli, M. Restignoli and G. Violini

Istituto di Fisica dell'Università - Roma

\author{
G. A. Snow \\ $C E R N$ - Geneva \\ (Nuovo Cimento, 45 A, $792(1966))$
}

In ref. $\left({ }^{5}\right)$

instead of Giacomell read Giacomelli

Every time

instead of FogGart read FrogGatT

At page 793. line 7 in the $X(Y)$ numerator instead of $m_{\mathrm{K}}$

read $m_{\mathrm{K}}^{2}$

At page 797 , line 1

instead of vicnity read vicinity

line 6

instead of solution II read solution III

In the table's footnotes

instead of $c_{4} \quad$ read $c_{6}$

In Table I, line 2

instead of oole read pole

In Table II, at $k=9.00 \mathrm{GeV} / \mathrm{c}, c_{3}=-\mathbf{7 6 . 4 0} \pm 0.69$ and $D_{-}=-1.96 \pm 3.74$. 